\title{
Teaching Professional Behavior
}

\author{
Gail A. McFarland, CNMT, RT(CT) ${ }^{1}$, Richard G. Hoylman, MM, CNMT ${ }^{2}$, Jennifer L. Prekeges, CNMT ${ }^{1}$, and \\ Vanessa R. Bennett, CNMT $^{2}$ \\ ${ }^{I}$ Nuclear Medicine Technology Program, Bellevue College, Bellevue, Washington; and ${ }^{2}$ Nuclear Medicine and Molecular Imaging \\ Program, Oregon Institute of Technology, Klamath Falls, Oregon
}

The goal of this article is to discuss the teaching of professional behavior to nuclear medicine technologists. The focus is on the present-day student situation and practices in the programs at Bellevue College and at Oregon Institute of Technology. Professional behavior is defined, and ways to communicate and assess it are described. Additionally, approaches to remedy unprofessional behavior are presented. The needs and expectations of clinical sites and of future employers of nuclear medicine graduates, as well as current avenues for promoting professionalism, are also discussed.

Key Words: professionalism; professional behavior; soft skills

J Nucl Med Technol 2020; 48:317-325

DOI: 10.2967/jnmt.120.244095

$\mathbf{E}$

ducators in the health and medical professions began about 3 decades ago to consider the importance of formal training in professional skills and practice (1). During the 1990s, prominent medical educators began addressing the need for curriculum and competencies pertaining to professionalism (2). Health education experts continue to express the need to teach professionalism and emphasize behaviors that qualify as professional, and much has been done to instill competencies that pertain to these concepts.

In discussions among nuclear medicine educators and other professionals who work with students, the topic comes up frequently that "today's students don't get it" when it comes to behaving professionally. Previous generations learned good behavior, norms, values, and workplace expectations independently, before as well as during their nuclear medicine education (3). Earlier cohorts of students readily mirrored the desirable behavior of their role models in the health professions (1). We do not see this happening nearly as much among students entering health-care programs more recently. This perception is borne out by research, which shows that current generations of students in the health professions need to be formally taught to under-

\footnotetext{
Received Feb. 24, 2020; revision accepted May 1, 2020.

For correspondence or reprints contact: Gail A. McFarland, Bellevue College, 3000 Landerholm Circle S.E., Bellevue, WA 98007.

E-mail: gail.mcfarland@bellevuecollege.edu

Published online Jun. 9, 2020.

COPYRIGHT (C) 2020 by the Society of Nuclear Medicine and Molecular Imaging.
}

stand and practice professional behavior (4). This is in addition to the colossal task of acquiring the technical skills and knowledge needed to be successful in their first jobs. This change may arise from generational differences as well as a rapid influx of new technology and unprecedented access to information. It may also be the result of changes in the health-care marketplace and greater diversity of ideas and practices. However, it is established that unprofessional behavior during training in the health-care professions correlates with ongoing unprofessional behavior in professional practice (2).

This paper describes how 2 nuclear medicine technologist (NMT) programs, at Bellevue College (BC) in Washington and Oregon Institute of Technology (OT) in Oregon, address the teaching and evaluation of professionalism. These 2 institutions provide an interesting point of comparison, for while they are close in proximity (relatively speaking, for the western half of the United States), their circumstances are quite different. OT is a 4-y public university located in a rural part of south-central Oregon. Students attending OT are more likely to be in the traditional college age range and following a typical path from high school to college to choosing a profession. $\mathrm{BC}$, on the other hand, is located in a major urban area. Although BC does offer a range of applied-science bachelor's degrees, including one in radiation and imaging sciences, it is primarily a community college. Many students at BC are older and are returning to school to change careers. Others are on the more standard community college path. And some are very young, having started their college careers while still in high school. BC has wide diversity as well in regard to ethnicity, language skills, and physical and mental abilities.

These 2 NMT programs reflect these broader demographic trends. In addition, the programs are set up quite differently. Students in the BC program bring prerequisites from many colleges and then spend $18 \mathrm{mo}$ in the nuclear medicine associate degree program. Clinical rotations are intermingled with classroom time, with 2 major rotations and several specialty rotations. OT students, on the other hand, more commonly earn their prerequisites and take their nuclear medicine courses during their time at OT. They have some clinical rotations in their second and third years, but the primary clinical experience is during the fourth-year externship. Thus, both the underlying student population and the experiences of the NMT students are 
dissimilar, and yet the 2 approaches to teaching professionalism are congruent.

\section{DEFINING PROFESSIONALISM}

Our first task is to define professionalism. Presently, there is ambiguity in the literature and in the minds of practicing professionals as to what constitutes professionalism and professional behavior for those who are in training in the health professions (5). Sometimes professionalism is presented as idealistic concepts rather than concrete actions (6). Sattar (7) describes professionalism as "attributes, behaviors, and commitments, which characterize a profession." Instructors and clinical staff who work with students are quick to identify certain activities and conduct as unprofessional (although without an identified standard). To students, on the other hand, it is often not intuitively obvious as to what constitutes professionalism or lack thereof, especially when faced with an overload of technical information and other expectations. Ambiguity exists also in how to present professionalism concepts to students and how to evaluate and deal with incidences of what is deemed to be unprofessional conduct.

Professional behavior covers a wide range of standards and practices beyond ethics or competency in one's job responsibilities. It involves attitudes and practices that serve the patient above one's personal needs and desires (8). van Luijk, Gorter, and van Mook (9) describe the central core of professionalism as "the values and norms" of one's profession. Nortje and De Jongh (5) refer to professional behavior in health professions as "the contract between medicine and society at large." These broader concepts can be subdivided into 3 subdomains: dealing with oneself, dealing with others, and dealing with tasks and work (9). There is not, however, a simple list of concise behavioral constructs that universally fall into the 3 professional behavioral domains for health-care professionals.

To further complicate the discussion, behaviors are subjective and open to individual interpretation as to what they are and what their level of importance is. Consequently, it is important to identify these domains of professional behavior specific to our industry in consultation with our advisory boards, clinical sites, and those who employ our graduates.

In an educational program for NMTs, a key part of professional behavior is integrating oneself into the health-care team. This behavior translates directly to employability. A 2009 survey of OT's clinical partners (3) produced the following list of characteristics that they would look for in hiring an OT graduate: an excellent work ethic; reasonable intelligence; the ability to solve problems and think critically, retain learned information, maintain focus despite outside distractions, and adapt to changing situations and environments; willingness to resolve any conflicts in a healthy way, to be team player, to treat every patient with respect and care, and to admit mistakes and take ownership of them; a desire to get along with everyone, to show patients that they care about them, and to assume responsibility for solving problems themselves, seeking outside help only after they have exhausted all options; professional behavior with patients and coworkers; good technical skills with equipment and cameras; enthusiasm; flexibility in work schedules (willing to work weekends and late shifts); a positive outlook and can-do attitude; the courage to voice concerns or opinions if they differ from those of the group; and a genuineness and sincerity in his or her work. Of this long list of desirable attributes, only a few relate to technical knowledge and skills. Most fall into the category of professionalism.

\section{TEACHING PROFESSIONALISM AT BC}

At BC, aspects of professional behavior are an integral part of the student handbook. Students are given behavioral instructions at the beginning of the program and are coached throughout the program on how to interact in the clinical setting. However, we have observed that directives for behaving professionally are not foremost in the minds of all students on a daily basis, and some are not consistently adhering to policies relating to attendance, team participation, and academic due dates, among others. Students also bring individualized interpretations of their student role and what constitutes professional behavior. Addressing and remediating professional behavior issues has been an ongoing endeavor and continues to present challenges for instructors. Our aim is to identify unprofessional practice early on and deliver ongoing interventions. That way, students have the opportunity to overcome barriers to successfully working as team members at clinical nuclear medicine sites. Those who are successful as team members more easily develop the behaviors and practices, as well as the necessary set of technical skills, that will make them employable in the capacity of NMTs.

The student handbook presents professional behavior requirements in several contexts and locations. Concepts related to technical skills (the "dealing with tasks and work" domain), interpersonal communications (the "dealing with others" domain), and professional behavior (the "dealing with self" domain) are all introduced in the "Program Goals" section. Specific behavioral concepts are presented in the "Expectations for Student Success" section. The "Student Responsibilities" and "Attendance Policy" sections present obligations that students must fulfill throughout the program that fit into all professionalism domains. The "Disciplinary Policies" section covers what may happen in the case of serious misconduct issues. The "Professional Behavior in the Clinical Setting" section covers specific expectations for personal conduct at each clinical site. During program orientation, students are given activities to demonstrate an understanding of expectations.

Practicing professional behavior as described in the handbook is expected throughout assigned internships at multiple clinical sites. Students are evaluated by their supervising technologists with respect to various aspects of professional behavior using a standard weekly evaluation form (Fig. 1). This form is the primary tool for communicating behavioral 


\begin{tabular}{|c|c|c|c|c|c|c|}
\hline \multirow[t]{3}{*}{ WEEKLY EVALUATION } & \multicolumn{3}{|l|}{ Student:_ } & \multicolumn{2}{|l|}{ Evaluator: } & Date: \\
\hline & \multicolumn{2}{|c|}{\begin{tabular}{|l} 
Seldom meets \\
expectations
\end{tabular}} & $\begin{array}{l}\text { Occasionally meets } \\
\text { expectations }\end{array}$ & $\begin{array}{l}\text { Usually meets } \\
\text { expectations }\end{array}$ & \begin{tabular}{|l|}
$\begin{array}{l}\text { Consistently meets } \\
\text { expectations }\end{array}$ \\
\end{tabular} & \begin{tabular}{|l|}
$\begin{array}{l}\text { Goes well above } \\
\text { usual expectations }\end{array}$ \\
\end{tabular} \\
\hline & \multicolumn{2}{|l|}{0} & 1 & 2 & 3 & 4 \\
\hline \multicolumn{7}{|l|}{ Professionalism } \\
\hline \multicolumn{7}{|l|}{ Dependability } \\
\hline \multicolumn{7}{|l|}{ Patient care } \\
\hline \multicolumn{7}{|l|}{ Initiative } \\
\hline \multicolumn{7}{|l|}{ Reception of instruction } \\
\hline \multicolumn{7}{|l|}{ Teamwork } \\
\hline \multicolumn{7}{|l|}{ Patient interaction } \\
\hline \multicolumn{7}{|l|}{ Use of own protocol manual } \\
\hline \multicolumn{7}{|l|}{ Ability to complete assigned tasks } \\
\hline \multicolumn{7}{|l|}{ Care of equipment } \\
\hline \multicolumn{7}{|l|}{ Reasoning ability } \\
\hline \multicolumn{7}{|c|}{ Comprehension of tasks performed } \\
\hline \multicolumn{7}{|l|}{ Accuracy } \\
\hline \multicolumn{7}{|c|}{ Comments from the clinical instructor } \\
\hline \multicolumn{2}{|c|}{ An accomplishment this week: } & \multicolumn{3}{|c|}{ A goal or focus for next week: } & \multicolumn{2}{|l|}{ Other comments: } \\
\hline \multicolumn{2}{|l|}{ Evaluator Signature: } & \multicolumn{4}{|c|}{ Student Signature: } & \\
\hline Date: & & & & & & \\
\hline
\end{tabular}

FIGURE 1. Weekly evaluation form used during BC clinical rotations.

expectations in the $\mathrm{BC}$ program. Additionally, students are given a professional writing assignment each quarter to reflect on a specific theme. Quarterly themes include team interactions, patient communications, self-reflection, and critical thinking (Supplemental Fig. 1; supplemental materials are available at http://jnm.snmjournals.org). Reflection on specific themes facilitates goal setting, reminds the student to revisit areas for improvement, and builds the student's identity as a nuclear medicine professional.

Professionalism during didactic education is also an expectation. At BC, the Canvas educational platform (Instructure, Inc.) is useful for reinforcing professionalism guidelines. Instructors use Canvas for posting required materials, setting due dates and expectations for student submissions, and providing helpful external links and information. Students upload assignments, take online examinations (a valuable skill for board preparation), and track their progress through each course. Canvas also provides mechanisms for communication and sharing between students and instructors during clinical education, as well as a convenient way to submit clinical assignments. The program has started requiring an introductory Canvas workshop to ensure that all incoming students fully understand the technical workings of this system.
Throughout the BC nuclear medicine program, students are introduced to more advanced professional concepts and opportunities through lectures and conferences. One example is joining and participating in professional societies, especially the Society of Nuclear Medicine and Molecular Imaging (SNMMI). Students obtain free trial memberships in the SNMMI. Benefits include access to journals and bestpractice protocols, as well as information about scholarships. The SNMMI website also includes a student technologist area. A future benefit of starting this relationship early in their career is that professional society members have greater opportunities for continuing education and professional development, as well as access to research and new knowledge in their field.

Students are also given the chance to interact with outstanding professionals. Interaction with nuclear medicine physicians is encouraged with a read-room competency. All four of us who are authoring this paper agree that over the course of our clinical careers, every opportunity to analyze cases with doctors made us better technologists. The radiopharmacy course is taught by a radiopharmacist who is also an NMT, modeling the potential for advancement in the field. The program also broadens understanding of all 
that is included in nuclear medicine through the use of guest speakers working in areas related to nuclear medicine, providing a variety of perspectives and increasing awareness of opportunities and roles for NMTs. These speakers have included a health physicist, a PET pharmaceutical specialist, a nuclear medicine supervisor, and a cardiologist with imaging expertise.

\section{BC EVALUATION OF STUDENT PROFESSIONALISM}

At BC, students engage in blocks of didactic education alternating with clinical assignments. Didactic courses are evaluated with formal grades and written feedback from faculty. With clinical education, students are provided early feedback, with weekly evaluations and summaries of progress at the end of the term. The weekly form (Fig. 1) may be completed by any of the clinical technologists who work with students. Each week, students receive documented feedback that they can act on for immediate positive results. They sign off on the form, verifying that they have seen the feedback. At the end of the clinical quarter, weekly evaluations are compiled along with competency accomplishments, competency quiz results, professional writing assignments, and other expectations, and a letter grade is determined.

The following sections describe basic aspects of the 3 domains of professional behavior that are included in the weekly and quarterly evaluations.

\section{Dealing with Self}

A critical aspect of dealing with oneself is accepting the feedback or constructive criticism delivered by clinical staff (9). Successful student technologists are able to accept constructive criticism without argument or denial and use it to improve personal practices. We have often observed that progress is stifled if students are unwilling to accept criticism gracefully or become defensive when corrected.

Another important "self" concept is self-reflection (9). Students must be able to honestly reflect on topics pertaining to personal growth, including identifying a realistic starting point, acknowledging errors and deficiencies, learning lessons from situations, and accepting criticism, in order to make progress toward functioning as an entry-level NMT. A self-reflection writing assignment is given during the third quarter of clinical education. Students who fail to acknowledge their personal learning processes and errors tend to demonstrate lower success with various aspects of clinical practice. Course assessment revealed that those who earned higher scores on the self-reflection assignment also made better progress with earning competencies.

\section{Dealing with Others}

Important aspects of dealing with others include teamwork, patient care, and patient interactions. The $\mathrm{BC}$ program puts considerable emphasis on interactions with patients, including empathetic communications and intercultural understanding. We also strongly stress the need to form team relationships with and develop the trust of staff at assigned clinical sites.
Most students who enter nuclear medicine are focused on patient care and needs and adapt quite well to these aspects of clinical practice. Teamwork, on the other hand, is an area of struggle for some students, who fail to recognize its necessity at clinical sites. Feedback from clinical staff and guidance from clinical instructors are crucial in helping a struggling student achieve self-efficacy for working on teams.

\section{Dealing with Tasks and Work}

There are several expectations that relate to students' management and performance of tasks and work responsibilities. These include making use of a personal protocol manual, demonstrating initiative, exhibiting good reasoning, and completing assigned tasks. None of these categories apply to a specific technical skill, but all are relevant to students' efforts in managing the set of skills and tasks that they must learn during clinical education. Dependability (including timeliness and staying on task) is assessed with the weekly evaluation and with the Trajecsys (Trajecsys Corp.) clinical tracking system. At BC, Trajecsys is the platform for tracking electronic student time records and monitoring student clinical participation and accomplishments. Instructors actively monitor student time-recording habits and intervene in the event of inaccurate recording or other problems. Accuracy and honesty with records are values of the BC NMT program.

School work is a component of the domain of dealing with work and tasks, and performance in this domain reflects how well students manage their dual responsibilities to both the program and their clinical internship (9). BC instructors have observed new negative trends in student time management and dependability with respect to homework assignments and course projects. It is common for a fraction of the class to be chronically late in submitting work. Computer technology can have both positive and negative effects. Online teaching platforms improve accessibility and flexibility for students. On the other hand, it seems easier or more acceptable to submit late work in an online environment. Instructors teach professional behavior with course work by emphasizing expectations at the beginning of the program and of each course and by firmly adhering to late-work submission policies and appropriate use of Canvas. The easy availability of materials produced by others increases opportunities for plagiarism. Writing submissions are linked to VeriCite (Turnitin), which checks for plagiarism. Later in the program, several didactic courses are offered in a hybrid or online format, giving students instructions on success in this environment as well.

\section{TEACHING PROFESSIONALISM AT OT}

At OT, professionalism skills, like technical skills, are discussed, taught, evaluated, and modeled by faculty and clinical staff. Students are given multiple opportunities to demonstrate and modify their competency in these skills over several months, with feedback from faculty and clinical staff. Program expectations, including professionalism, are communicated to students early and often, including consequences for failing to meet those expectations. 
The importance of professionalism is introduced to students immediately on acceptance into the program in their sophomore year, after completing a premedical-imaging year. Students are given a program orientation handbook, developed in consultation with our clinical sites and industry advisory board. Faculty review and update the handbook annually for content. Faculty also review and discuss the expectations in the handbook with the students the first week they are in the program and subsequently refer to these expectations at the beginning of each academic term. The handbook includes policies, procedures, and standards that students are required to follow, both on campus and during the clinical rotations. In addition, it describes professionalism skills and competencies that students are expected to demonstrate throughout their educational experience at OT. The handbook describes how and when students will be evaluated with regard to these professionalism skills and behaviors, as well as describing the consequences for failing to meet these expectations.

Faculty develop assignments or projects that address each skill or behavior (Supplemental Fig. 2). These assignments or projects are then embedded within the didactic, laboratory, or clinical curriculum where they make the most logical sense. In some courses, only one skill is taught. In other courses, multiple skills may be taught. Each assignment or project addresses a particular skill or behavior. An assignment may be completed individually or as a team, depending on the skill or behavior.

The assignment that teaches critical thinking as related to image interpretation is a good example. Student must follow a strict method of viewing images with this process: what do I see (observation), what do I think (interpretation), and then finally what do I do (application, other images, or studies). Students initially want to jump immediately to interpretive conclusions. However, we work diligently with students to discipline themselves in this process by slowing down and spending the necessary time to identify what they see on the images first. This process includes starting at the top left of each image and working to the bottom right of each image. We do this for images viewed in lecture as well as in lab. This practice of describing what they see sets the necessary foundation for students to more accurately move to discussing what they think (interpretation) and then what they should do (application) for each study. This assignment is embedded in all our procedures courses. We work with our clinical instructors to follow this process with the students in clinical training as well.

\section{OT EVALUATION OF STUDENT PROFESSIONALISM}

At OT, each student undergoes a professional evaluation (Fig. 2) at the end of each term, beginning on campus and continuing throughout their clinical externship. The professional evaluation is first and foremost a tool for students, faculty, and clinical staff. The purpose of the evaluation is to encourage a student's progress and competency in each skill or behavior. It is also used to identify deficiencies in a skill or behavior.

The professional evaluation lists each category of skill or behavior to be assessed and a grade scale to be applied to each category: "progressing beyond expectations," "progressing as expected," "progress is marginal," or "fails to meet minimum expectations." The professional evaluation is graded and accounts for part of the student's grade for that course.

The professional evaluation tool used in the students' 11mo clinical externship is essentially the same as that used on campus, with minor differences. This consistency between didactic and clinical training is helpful for the student. To achieve consistency between evaluators, a workshop is conducted annually at our advisory board meeting to train clinical evaluators on how to use this tool.

During the evaluation process, the clinical instructor completes the professional evaluation and schedules a meeting with the student to go over the results. The meeting is conducted one on one, or at the most two on one, and is private. The student is asked to complete a self-evaluation as well. When the evaluator and the student meet, the purpose of the meeting is to review the student's progress, to encourage the student, and to identify any discrepancy between the student's understanding and the evaluator's understanding. The evaluator may offer suggestions and identify deficiencies in performance that the student must address.

There are some skills or behaviors that OT faculty and clinical instructors seem to identify most often for improvement. These include critical thinking, problem solving, multitasking, attitude, and behavior issues. The professional evaluation tool directs the clinical instructors in assessing these behaviors. More mundane issues, such as occasional cell phone use or irregularities in attendance, are also addressed in the tool.

\section{TEACHING AND EVALUATING PROFESSIONALISM AT A DISTANCE}

OT is a small polytechnic university located in rural Southern Oregon. Students in the nuclear medicine and molecular imaging program spend 3 y completing didactic and laboratory requirements on campus, as well as clinical rotations at Sky Lakes Medical Center across the street from the university. However, for their fourth and final year of training, students spend 11 mo of clinical training in a hospital affiliated with the university. Many of these clinical sites are located within a reasonable driving distance of the university, but some are much farther away. The physical distance from the university presents some challenges when it comes to addressing student progress (or lack of progress) in the clinical environment when an on-site, same-day visit is not always possible.

To address the teaching and evaluation of professionalism at long distances, it is imperative that students be well prepared-before they leave the university-for the challenges that await them. It is also essential that the program work closely with the clinical site and clinical instructors to provide the necessary training and support and consistently hold students accountable for meeting the standards of professionalism required by the program.

\section{Clinical Externship Preparation}

In addition to embedding the teaching and evaluation of professionalism skills within the curriculum, OT several 
OREGON TECH

Medical Imaging Department

NMT PROFESSIONAL EVALUATION (2016 - 2017)

Student's Name: Course: Date:

Faculty/Evaluator: Room:

Performance Rating: $\quad$ Use the following scale to evaluate the student. A number range may be used.

$\begin{aligned} \mathbf{9 3 - 1 0 0} \% & \text { Progressing beyond expectations } \\ \mathbf{8 4 - 9 2} \% & \text { Progressing as expected } \\ 75-83 \% & \text { Performance is marginal } \\ 0 \% & \text { Performance fails expectation for skill } \\ & \text { level }\end{aligned}$

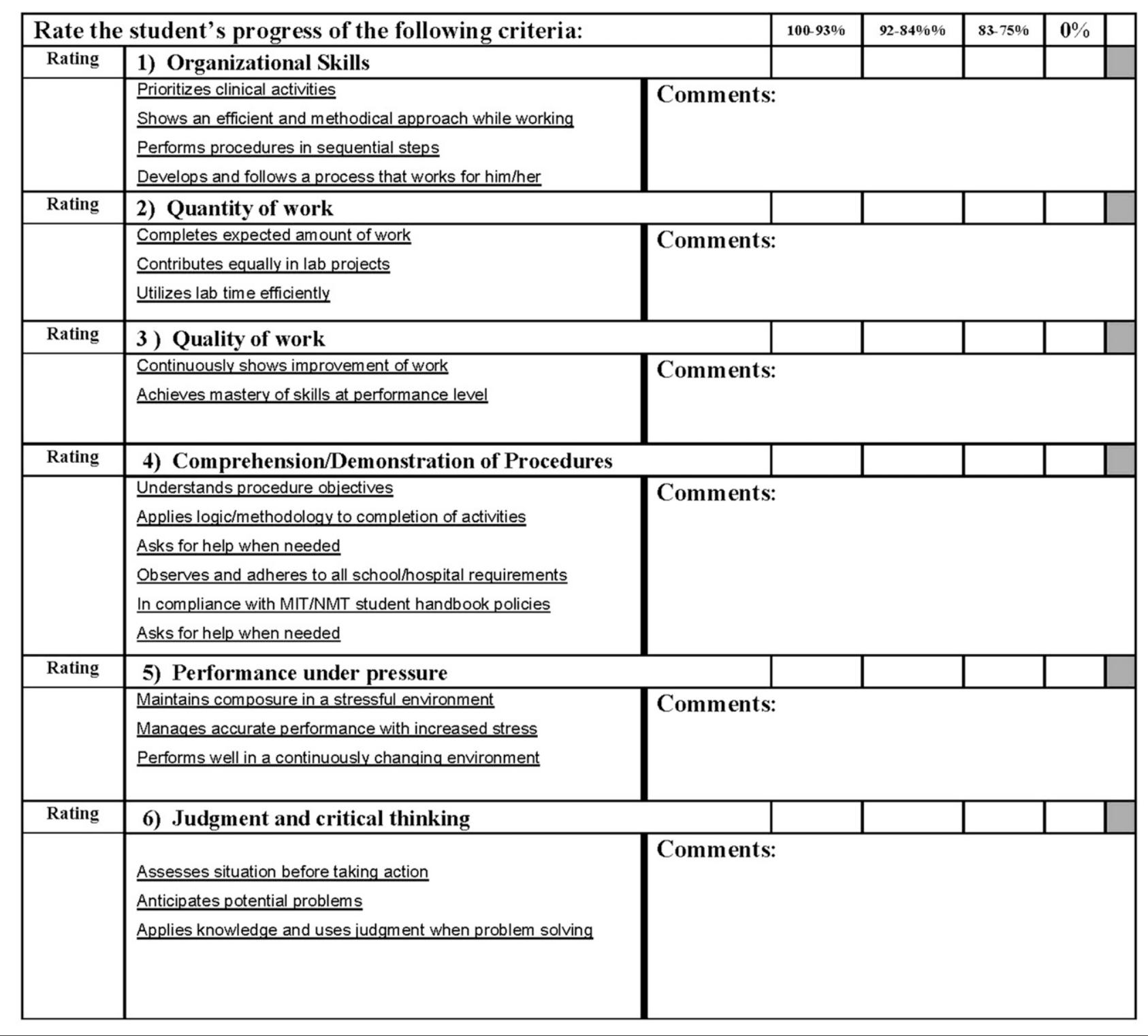

FIGURE 2. Professional evaluation tool used by OT both on campus and during clinical externship. 
years ago added an extern-preparation course just before students leave campus for their 11-mo clinical externship. In this course, the first $4 \mathrm{wk}$ of the 10 -wk term is spent discussing emotional intelligence and the importance of developing grit and perseverance, providing students an opportunity to self-reflect on these skills and competencies and to develop strategies to improve.

In the remaining $6 \mathrm{wk}$ of the term, the course summarizes many of the professionalism topics discussed during the previous $2 \mathrm{y}$, and students engage in several self-reflection exercises to demonstrate growth and areas for improvement. This course stresses that professionalism is a process that takes time, intention, and feedback from mentors. The feedback has been overwhelmingly positive, and the students insist that the school continue to offer this course.

\section{Clinical Instructor Training}

Each May, before the beginning of the clinical externship, the program invites clinical instructors to an annual advisory board and clinical instructor workshop. Personnel from distant clinical sites who cannot attend in person join the meeting via video conferencing.

The clinical instructor workshop is an opportunity to update clinical sites on any changes in the curriculum, in clinical training, or in the industry and to provide continuing education to clinical instructors. Recent topics have included emotional intelligence, grit, what separates a good from a great clinical instructor, and incorporating CT and MRI training into the externship. Workshops are held on how to teach and evaluate professionalism and how to use the professional evaluation tool effectively and consistently. Feedback from clinical sites is solicited regarding best practices and challenges with student training. It is here that some of the most important work is done. At the conclusion of the workshop, clinical instructors are well prepared to identify and address issues of professionalism in the clinical environment and to evaluate each student in a manner consistent with OT practices and standards.

\section{Weekly Wrap-up Sessions}

At the end of each clinical week, the clinical instructor meets with the student to review progress. These weekly wrap-up sessions may last only 10-20 min, but they allow the student and the clinical instructor to review how the student is progressing toward examination competencies, discuss any relationship issues within the department, discuss any issues related to professionalism, and help the student set, review, and meet weekly goals. Potential issues are addressed so that there are no surprises for the student at the end of the term. In essence, the students are coached throughout the term, and it is up to them to demonstrate competency. It is important to reiterate that the clinical site and the university cannot hold students accountable for meeting standards or expectations that were not communicated to the student before starting clinical training. Expectations and consequences for failing to meet them need to be communicated both verbally and in writing before the start of clinical training.

\section{Weekly Student Updates}

In addition to the weekly wrap-ups with the clinical instructor, students provide weekly updates to university faculty on their progress. This includes technical accomplishments and interactions with staff and patients, as well as any issues that might have arisen. These updates allow faculty to identify potential issues before they become problems and to work with the student and the clinical site to address these potential issues. Mentorship on site from the clinical instructor, along with mentorship at a distance from the faculty, helps the student navigate the challenges of clinical training for $11 \mathrm{mo}$. Honest, frequent communication is the key.

\section{On-Site Clinical Visit}

Faculty in the program conduct an on-site clinical visit with the student and clinical instructor during the 11-mo externship. The goals for this site visit are to encourage the student, review previous goals, set new short- and long-term goals, address any current or potential issues, strengthen the partnership with our clinical site, and make sure that the student, clinical instructor or site, and faculty are all on the same page regarding the students' progress and plan for success.

\section{OT INTERVENTION PRACTICES}

The primary goals of the OT nuclear medicine and molecular imaging program are to educate and train future NMTs to be valued colleagues and to provide the highestquality patient care possible. When students first enter the program, and frequently throughout the program, they are informed that everything the instructors do, including teaching and evaluating professionalism, is to accomplish these goals. Faculty want students to be successful on campus, on their clinical externship, and ultimately as contributing members of the nuclear medicine community. Faculty develop and manage the curriculum and clinical externship sites with these goals in mind. Students are reminded often that this is their instructors' primary goal for them and that reaching it requires evaluation of professionalism and, on occasion, performance improvement and remediation of inappropriate behaviors.

Students are routinely reminded that the professional evaluation process, including the probation policy, is not intended to be primarily punitive. In fact, instructors emphasize that it is their hope it is never punitive. Levels of discipline in the probationary policy are described below.

\section{Warning}

If a student fails to meet the minimum expectation for one or more skill levels on the professional evaluation, the remediation process begins with a verbal and written warning. The faculty or clinical instructor sits down with the student to discuss the student's lack of progress. Potential actions that the student, faculty, or clinical instructor can take to improve the student's performance are discussed and implemented. The goal is to help the student perform better. This warning may occur at any time during the student's 
training and education-in the weekly wrap-up session or during the end-of-term professional evaluation.

\section{Probation}

If students are unable or unwilling to improve their skill level, or to remediate behavior above the minimum level of "progress is marginal," then they are put on probation status. Probation is the process by which remediation must occur. The terms of probation should be specific, including the time frame in which remediation is expected. Students must provide their signature acknowledging that they have received the probationary terms. At the end of the probation period, they are reevaluated. If they have met the terms of probation, they receive their new grade for the evaluation and are taken off probation.

Faculty and clinical instructors are trained annually at the clinical instructor workshop on how to use the professional evaluation and are cautioned to use the probation policy only after verbal and written warnings have failed to achieve the desired effect.

\section{Dismissal}

At the conclusion of the probation period, if students are unable or unwilling to improve their skills, or to remediate their behavior to at least the minimum level of "progress is marginal" on the professional evaluation, they are dismissed from the program.

\section{BC INTERVENTION PRACTICES}

$\mathrm{BC}$ has a strong focus on student retention and offers professional development courses for faculty on strategies to retain students and improve engagement and performance. These strategies have become a part of teaching practice with NMT faculty at BC. One tactic is early and assertive intervention when student issues surface. The BC early-intervention approach was aptly summarized by one staff member as "Nip a bad behavior in the bud, before it becomes a bad habit."

\section{Early Signs of Student Unprofessionalism}

"The eyes and ears of patients, visitors and health care team members are considered to be the most effective surveillance tools for detecting unprofessional behavior" (6). There are warning signs that present when a student is struggling with aspects of the nuclear medicine program. Early indications include consistent late homework submissions or absence from classes. During clinical education, clinical-staff feedback is the first indication of a problem. Staff typically email instructors informally and document poor performance formally with the weekly evaluation. Common signs of student difficulties early in the BC nuclear medicine program are unwillingness to receive criticism and failure to acknowledge errors. Other signs are not adhering to attendance expectations at the clinical site or keeping inaccurate time records.

\section{Addressing Negative Feedback}

The literature supports the effectiveness of coaching students who have had documented occurrences of unprofessional behaviors (7). Instructors reach out to students about performance right away when an issue becomes evident. The intent is to advise them early on about the behavior in question, the context, and solutions so that they can reverse any negative patterns of behavior. Students are always invited to meet with instructors for help with academic work or other concerns. Instructors keep close tabs on weekly evaluations and other records for struggling students and request progress as needed from the clinical staff. Counseling notes are retained in the student records. One student had weekly phone meetings with the clinical instructor to monitor progress on behavioral issues, with the incentive of knowing that the phone meetings would end when it became evident that the desirable behavior had become habitual. Other students required instruction on how to correctly adjust incomplete time records and counseling on the appropriate use of Trajecsys entries and the consequences for time-card inaccuracies.

\section{Other Interventions}

Due dates for academic and clinical assignments are strictly enforced, with loss of points for being late. Past leniency regarding due dates allowed a few students to maintain a chronic habit of being late, which led to lower retention of material and lower performance in the clinic. Others believed that online work meant working at one's preferred pace and timeline, which led to missed assignments and loss of credit. For most NMT students, the loss of a few points has been a sufficient incentive for them to turn in their work to Canvas on time. BC instructors are now firm about due dates and about timely and accurate submissions to Canvas.

\section{PROFESSIONALISM REQUIREMENTS IN INDUSTRY}

As we consider how to teach professionalism, it is helpful to keep in mind our ultimate goal as educators, which is to produce NMTs who behave in a professional manner. Some opportunities to exhibit professional behavior come after graduation. It is worthwhile to keep these in mind.

\section{Investment in Self}

Dedication to lifelong learning is an important starting point for new graduates. Breen (10) describes the concept of lifelong learning as beginning one's career in nuclear medicine with the goal of a careerlong pursuit of continuing education. That is, an entry-level NMT must aim to stay current with rapidly advancing technology and evolving skill sets and should plan to pursue further educational goals. This process and this mindset are initiated in the educational program.

\section{Involvement in Professional Activities}

A prime way to maintain currency and to advance in one's profession is to actively participate in a professional society. Individuals demonstrate commitment to their profession by attending professional society meetings, reading 
journals, and earning continuing education credits. These types of activities lead one to think more deeply not only about the technical aspects of one's profession but also about one's responsibilities toward patients and employers. In addition, professional meetings present opportunities to meet people at various stages of their careers. For students, this widens their understanding of what they might aim for after graduation. Being involved in a professional society early in one's career results in higher levels of confidence and competence (11).

In nuclear medicine in particular, when student NMTs attend professional meetings they see technologists taking leadership roles on an equal footing with physicians. This motivates them to move beyond the attitude of "I'm just here to do my job" or "I'm just a tech" into the idea that "I can be a leader." Certainly one of the primary motives for teaching the soft skills of professionalism is the development of individuals who can step into leadership roles.

Professional organizations perform important functions. "The best professional associations, especially in highly regulated environments such as health care, help their members tackle contemporary challenges and keep up with ever-changing rules, requirements and standards" (12). Encouraging individuals to start becoming involved while they are still students increases the likelihood that they will continue to be involved throughout their careers, in turn benefiting all of us in the profession. This is an important and sometimes neglected part of our responsibility as educators.

\section{Research}

An excellent way to invest in oneself and one's profession is through scientific research. Some NMT programs, often those in university settings, have curricula that include research activities (13). Neither the BC program nor the OT program has been able to incorporate research activities into the coursework, but both programs recognize the potential benefit. Undergraduate research can be presented at regional and national meetings and can be published in peer-reviewed journals such as the Journal of Nuclear Medicine Technology. Technologists with research experience have a greater sense of the changing nature of the field and are better prepared to read and evaluate research throughout their careers. Activities that are central to research complement the soft skills of professionalism.

\section{Clinical Instructors}

Many students will ultimately become clinical instructors themselves. An emerging topic in professional education is educating the educator on how to teach professional behavior to students. This is particularly a problem with technologists in the health-care professions, who frequently have no background in education whatsoever and are simply expected to teach as a part of their employment (14). Training on how to handle unprofessional behavior, for both academic faculty and clinical instructors, will be a key to improving professional education in NMT programs (15). Similar to OT, BC has 5 health sciences programs that annually offer a workshop to educate clinical instructors on BC's approaches to clinical education and their role as the on-the-ground instructors (15). This workshop always provides useful feedback from the clinical instructors, often resulting in material changes to practices that improve the programs at $\mathrm{BC}$.

\section{CONCLUSION}

The field of nuclear medicine and molecular imaging is, first and foremost, people-centric. As such, engagement with patients, their families, and other health-care professionals is required. Each of these interactions is an opportunity to reflect the values and mission of the organization. Consequently, the teaching and evaluation of professionalism, over and above technical training, are essential. In this paper, we have documented the methods we use to teach and evaluate professionalism as an integral part of both didactic and clinical training, in 2 disparate NMT programs. Important principles common to both programs include communication of expectations, enforcement of rules, regular interaction of program and clinical faculty, and a clear understanding of descriptors used in evaluations. Following these principles may not guarantee success but certainly makes success more likely.

\section{DISCLOSURE}

No potential conflict of interest relevant to this article was reported.

\section{REFERENCES}

1. Barnhoorn PC, Bolk JH, Ottenhoff-de Jonge MW, van Mook WN, de Beaufort AJ. Causes and characteristics of medical student referrals to a professional behaviour board. Int J Med Educ. 2017;8:19-24.

2. Cruess RL, Cruess SR. Teaching medicine as a profession in the service of healing. Acad Med. 1997;72:941-952.

3. Hoylman R. Go beyond technical skills and teach professionalism, Radiology Today. 2014;15:30.

4. Cruess RL, Cruess SR. Teaching professionalism: general principles. Med Teach. 2006;28:205-208.

5. Nortje N, De Jongh J. Professionalism: a case for medical education to honour the societal contract. S Afr J Occup Ther. 2017;47:41-44.

6. Cruess RL, Cruess SR. Professionalism is a generic term: practicing what we preach. Med Teach. 2010;32:713-714.

7. Sattar K. Ten questions to be answered before incorporating problem-based learning (PBL) into professionalism course. Educ Med J. 2019;11:59-69.

8. Hawick L, Cleland J, Kitto S. Sending messages: how faculty influence professionalism teaching and learning. Med Teach. 2017;39:987-994.

9. van Luijk SJ, Gorter RC, van Mook WNKA. Promoting professional behaviour in undergraduate medical, dental and veterinary curricula in the Netherlands: evaluation of a joint effort. Med Teach. 2010;32:733-739.

10. Breen IT. Encouraging lifelong learning: an educator's perspective on teaching and learning for the nuclear medicine technologist. J Nucl Med Technol. 2019;47: $120-126$.

11. Michael K, Tran X, Keller S, Sayles H, Custer T. Radiography student participation in professional organizations. Radiol Technol. 2017;89:20-26.

12. Schierhorn C. A wealth of resources: professional societies offer tools for learning and collaboration. Health Facil Manage. 2017;30:18-23.

13. Nielsen CJ. A research methodology curriculum for undergraduate students in nuclear medicine technology. J Nucl Med Technol. 2017;46:70-74.

14. Knight AW. How clinical instructor behavior affects student clinical engagement from a motivational perspective. J Nucl Med Technol. 2018;46: 99-106.

15. Prekeges J. Workshop on instructional skills in the clinical setting. J Nucl Med Technol. 2018;46:96-98. 